\title{
Frequency Control in a Hydroelectric Power Plant with Adaptive Neuro-Fuzzy Inference System-Based Modern Controllers
}

\author{
Rahma TABAKH ${ }^{1}$ (D) Hasan TIRYAKI ${ }^{2 *}$ (D) Nevra BAYHAN ${ }^{3}$ (D) \\ 1, 2, 3 Istanbul University - Cerrahpaşa, Electrical and Electronics Engineering Department, 34320, Istanbul, \\ Turkey
}

Geliş / Received: 05/04/2021, Kabul / Accepted: 07/06/2021

\begin{abstract}
In power systems, the constant frequency, constant voltage, and the power output are desired and determine the quality of the generated electrical energy. Therefore, frequency control is crucial in power systems. The parameters of conventional controllers used in power generation plants are determined according to the system's characteristics at the stage of installation, they cannot adapt to the changing system dynamics as the lifespan of power plants increases. Thus, studies on the automatic adaptation of controller parameters to the continuously changing system dynamics are needed. In this study, conventional PI and PID controllers applied to the power system for frequency control of a hydroelectric power plant were examined comparatively with Fuzzy Gain Scheduled PI (FGPI) controller and Adaptive Neuro-Fuzzy Inference Systembased PI (ANFIS-PI) and PID (ANFIS-PID) controllers in the simulation environment. The obtained results demonstrated that Adaptive Neuro-Fuzzy Inference System-based controllers were quite successful compared to the others.
\end{abstract}

Keywords: Power Systems, Frequency Control, Hydroelectric Power Plant, FGPI, ANFIS-PI, ANFIS-PID

\section{Uyarlanabilir Nöro-Bulanık Çıkarım Sistemi Tabanlı Modern Kontrolörlerle Bir Hidroelektrik Santralinde Frekans Kontrolü}

\section{$\ddot{O} \mathbf{z}$}

Güç sistemlerinde, tüketicinin beklentisi olan sabit frekans, sabit gerilim ve istenen değerdeki güç üretilen elektrik enerjisinin kalitesini belirler. Bu sebeple güç sistemlerinde frekans kontrolü oldukça önemlidir. Enerji üretim santrallerinde kullanılan klasik kontrolörlerin parametreleri kurulum aşamasındaki sistem özelliklerine göre belirlendiği için santral ömürleri arttıkça değişen sistem dinamiklerine uyum gösterememektedir. Bu istenmeyen durumu önleyebilmek için kontrolör parametrelerinin sürekli değişen sistem dinamiklerine kendiliğinden uyum gösterebilecek şekilde çalışmalara ihtiyaç duyulmaktadır. Bu noktadan hareketle enerji santrallerinde kullanılan kontrolörlerin ve parametrelerinin belirlenmesi konusunda yapılan bu çalışmada, bir hidroelektrik santralinin frekans kontrolü için güç sistemine uygulanan klasik PI ile PID kontrolörler, Fuzzy Gain Scheduled PI (FGPI) kontrolör ve Adaptive Neuro-Fuzzy Inference System tabanlı PI (ANFIS-PI) ile PID (ANFIS-PID) kontrolörler simülasyon ortamında karşılaştırmalı olarak incelenmiştir. Elde edilen sonuçlar Adaptive Neuro-Fuzzy Inference System tabanlı kontrolörlerin diğerlerine göre oldukça başarılı olduğunu göstermiştir.

Anahtar Kelimeler: Güç Sistemleri, Frekans Kontrolü, Hidroelektrik Güç Santrali, FGPI, ANFIS-PI, ANFIS-PID

\section{Introduction}

Electric power generation has become more critical with increasing demand from both domestic and industrial consumers. The control of electric power plants has also become more important due to the fact that sudden changes in consumer demand, malfunctions in some

\footnotetext{
*Corresponding Author: hasan.tiryaki@istanbul.tr
} 
networks and even deteriorations occurring in the system frequency can lead to severe damage to both the consumer and the energy supplier. Therefore, fluctuations in the system frequency should be kept within specified limits. Besides all these, the production cost of electricity increases, and also the economic life of the equipment inside the plant decreases due to fluctuations in the amplitude of the output signal. These are both inefficient and undesirable. The load-frequency controllers (LFC) can minimize the transient deviations by maintaining the real frequency and the desired output power of the system (Kocaarslan and Çam, 2002; Gheisarnejad and Khooban, 2019).

Around the world, the vast majority of electrical energy is observed to be produced in fossil fuel power plants such as thermal power plants, natural gas cycle power plants, nuclear power plants, and medical waste power plants. The damages and risks created by these power plants for the protection of the natural environment are known. Considering this situation, using hydroelectric power plants instead of fossil fuel power plants in energy generation is a necessity. The ability of hydroelectric power plants to produce energy without using fuel both contributes to the protection of the environment and increases the continuity and efficiency of the produced energy (Qian and Jianqiang, 2013; Tabakh, 2020). Energy generation must first be based on clean energy sources to meet the ever-increasing demand for energy with a sufficiently redundant supply. The fact that it is a renewable resource, has a minimal environmental impact, does not cause environmental pollution, has low operating and maintenance costs, and most importantly, is a national resource that supplies reliable energy dramatically increase the importance of hydroelectric energy (Eke,2004; Sevilgen and Erdem, 2014).

To date, various studies have been conducted on the control of hydroelectric power plants. In the study conducted by Shahgholian in 2017, a power system stabilizer application was proposed for load-frequency control in hydroelectric power plants (Shahgholian, 2017). Rinaldi et al. used the sliding mode observers method for an energy network consisting of thermal and hydroelectric power plants in the study they conducted in 2018 (Rinaldi et al., 2018). The study conducted by Aurelien et al. in 2019 used the PID Controller, Internal Model Control, and Robust Structure Theory methods for frequency control in a hydroelectric power plant (Aurelien et al., 2019). Simani et al. used fuzzy logic control techniques for loadfrequency control in two area systems consisting of wind turbines and hydroelectric power plants in the study they conducted in 2019 (Simani et al., 2019). A fuzzy logic-based selftuning PID controllers was utilized and optimized by GA for the load frequency control (Ahmadi et al., 2020). The bat algorithm was presented (Yuniahastuti et al., 2016) to tune the controller Capacitive Energy Storage. To optimize the controller parameters in an isolated hydropower system, the cuttle-fish method was developed (Khari et al.,2020).Unfortunately, conventional controllers are still used in the existing hydroelectric power plants, and since their parameters are determined according to the features of the system at the stage of initial installation, they cannot adapt to the changing system dynamics as the lifespan of power plants increases. This situation causes efficiency loss in power plants and their serving below available capacities. In order to prevent this undesired situation nowadays when energy loss is unacceptable, it is necessary to design controllers used in power generation plants with modern controllers in order to provide their self-adaptation to the continually changing system dynamics, or it is necessary to replace old controllers with modern controllers (Electricity Generation Company, 2019).

In this study, the conventional controllers such as, PI and PID controllers have been replaced with FGPI controller, ANFIS-PI and ANFIS-PID controllers in the frequency control 
application of a hydroelectric power plant model which had not been applied in a single area hydroelectric power plant previously and the obtained results were examined.

\section{Modeling of a Hydroelectric Power Plant}

To provide quality (constant frequency, desired voltage, and power) service to the consumer of electric energy, the power system must remain constant and reliable against disruption in a very wide range. Electric power systems are complex and dynamic systems. Since hydroelectric power plants in the power system are open only to small load changes during their regular operation, a linearized model of the plant can be used in the analysis. The modeling of a hydroelectric power plant has been examined in two parts as the turbine model and generator model (Tabakh, 2020; Eke, 2004).

\subsection{Turbine model}

The hydroelectric power generation system displays a high grade and nonlinear behavior. Appropriate mathematical models are tools necessary for the simulation of such systems. When modeling a hydraulic turbine, two assumptions are addressed in particular. The first assumption is the neglect of the compressibility of water; the second assumption is the elastic water load effects (Vournas and Zaharakis, 1993). In the analysis of turbine dynamics, the effects of water load are also added. Mainly these effects make the penstock model between the dam and the turbine inlet difficult. Furthermore, the turbine-penstock mathematical model can be examined as linear and nonlinear models. The obtained models are essential for turbine control. In this study, research was conducted on the linearized model (Eke,2004).

Since linear models are obtained within the framework of the working point, they can also be called small-signal models. These models are inferred from the fundamental equations of turbine and penstock characteristics with some simplifying assumptions for approximate modeling (Tabakh, 2020; Tiryaki and Gün, 2019; Naghizadeh et al., 2012; Eke,2004).

The employed model is used in the small-signal analysis and studies on control system design. The non-elastic water load transfer function can be obtained by linearizing the penstockturbine basic equations. Moreover, small changes in mechanical power depend on changes in the distributor opening (Tabakh, 2020; Tiryaki and Gün, 2019; Naghizadeh et al., 2012; De Jaeger et al., 1994; Eke,2004). These results were demonstrated in the first-order transfer function equation in Equation (1):

$$
\frac{\Delta \mathrm{P}_{\mathrm{m}}(\mathrm{s})}{\Delta \mathrm{G}(\mathrm{s})}=\frac{1-\mathrm{T}_{\mathrm{W}} \mathrm{s}}{1+\frac{1}{2} \mathrm{~T}_{\mathrm{w}} \mathrm{s}}
$$

where $T_{w}$ was defined as the water time constant, $\Delta P_{m}$ as the change in mechanical power of the turbine, and $\Delta \mathrm{G}$ as the position of the turbine water inlet distributor. $\mathrm{s}$ is the Laplace operator.

\subsection{Generator model}

In the power system, the dynamic behaviors of generators are important. The generator converts mechanical power into electrical power at a suitable voltage and frequency. Since system frequency and active power balance are interconnected, load-frequency control is generally used in power systems. The generator model is also based on the frequency change response. In order to establish this model, motion and oscillation equations are used. 
The electrical model of the generator of which mechanical equations are known can be found with the help of oscillation equations of rotational inertia. Thus, the electricity production part is modeled with linear differential equations that can quickly respond to small disturbances.

The oscillation equation associates the rotor torque angle of the machine with the acceleration torque, and this is the difference between the shaft torque and electromagnetic torque. When a balance is achieved between the mechanical torque and electrical torque, the speed of the generator is made constant. Any imbalance between torques causes acceleration or deceleration in the machine. The equation of motion in a rotating body is given as follows (Tabakh, 2020; Tiryaki and Gün, 2019; Kundur et al. 1994):

$$
\mathrm{T}_{\mathrm{a}}=\mathrm{M} \propto=\mathrm{M} \frac{\mathrm{d} \omega}{\mathrm{dt}}=\mathrm{M} \frac{\mathrm{d}^{2} \delta}{\mathrm{dt}^{2}}=\mathrm{T}_{\mathrm{m}}-\mathrm{T}_{\mathrm{e}}
$$

where Ta was defined as the acceleration torque, $\mathrm{M}$ as the generator and turbine total moment of inertia, $\propto$ as the angular acceleration, $\omega$ as the angular velocity, $\delta$ as the generator phase angle, $t$ as time, $T_{m}$ as the mechanical torque, and $T_{e}$ as the electromagnetic torque. The equation of motion is obtained as the unit value by using the electrical rotor angular velocity (Tabakh, 2020; Tiryaki and Gün, 2019; Kundur et al., 1994):

$M \frac{d \bar{\omega}}{d t}=\overline{T_{m}}-\overline{T_{e}}$

Where $\bar{\omega}$ was defined as the normalized angular velocity, $\overline{T_{m}}$ as the normalized mechanical torque, and $\bar{T}_{e}$ as the normalized electromagnetic torque. Equation (3) should be arranged in terms of mechanical and electrical power instead of torque.

The electrical power equation dependent on torque is expressed as $\mathrm{P}=\omega \mathrm{T}$. By neglecting small oscillations around the working point and second-order terms, the following equation is obtained (Tabakh, 2020; Tiryaki and Gün, 2019: Kundur et al., 1994).

$\Delta \bar{P}=\overline{\omega_{0}} \Delta \bar{T}+\bar{T}_{o} \Delta \bar{\omega}$

where, $\Delta \bar{P}$ was defined as the normalized power change, $\overline{\omega_{0}}$ as the normalized initial angular velocity value, $\Delta \bar{T}$ as the normalized torque change, $\bar{T}_{o}$ as the normalized starting torque, and $\Delta \bar{\omega}$ as the normalized angular speed change. If the expressions of mechanical and electrical power and torque are put in Equation (4), Equation (5) is obtained (Tabakh, 2020; Tiryaki and Gün, 2019, Kundur et al., 1994).

$\Delta \overline{P_{m}}-\Delta \overline{P_{e}}=\overline{\omega_{0}}\left(\Delta \overline{T_{m}}-\Delta \overline{T_{e}}\right)+\left(\overline{T_{m_{0}}}-\overline{T_{e_{0}}}\right) \Delta \bar{\omega}$

where, $\Delta \overline{P_{m}}$ was defined as the normalized mechanical power change, $\Delta \overline{P_{e}}$ as the normalized electrical power change, $\Delta \overline{T_{m}}$ as the normalized mechanical torque change, $\Delta \bar{T}_{e}$ as the normalized electrical torque change, $\overline{T_{m_{0}}}$ as the normalized starting mechanical torque, and $\Delta \bar{T}_{e}$ as the normalized starting electrical torque. In the steady state, mechanical torque is equal to electrical torque ( $\overline{T_{m_{0}}} \cong \overline{T_{e_{0}}}$ ). Accordingly, by combining Equations (3) and (5) and assuming that the initial conditions are zero, the relationship between mechanical power, electrical power, and speed change is obtained as follows (Tabakh, 2020; Tiryaki and Gün, 2019; Kundur et al., 1994):

$\Delta \overline{P_{m}}-\Delta \overline{P_{e}}=M s \Delta \bar{\omega}$ 
In some cases, a more detailed generator model is required to take into account the power characteristics of the generator that feeds the isolated load source and of the local load. The most commonly used static model represents active power as the constant current and reactive power as the constant impedance. Loads consist of a wide variety of electrical elements, and since the system's short-time stability is concerned, using the static load model equations will be sufficient. In this case, the change in electrical power can be expressed as (Tabakh, 2020; Tiryaki and Gün, 2019; Kundur et al., 1994):

$\Delta \bar{P}_{e}=\Delta \bar{P}_{L}+\Delta \overline{P_{D}}$

where, $\Delta \bar{P}_{L}$ was defined as the normalized change in load, and $\Delta \overline{P_{D}}$ as the normalized change in electrical power due to damping. The change that occurs in power due to damping can be expressed as (Tabakh, 2020; Tiryaki and Gün, 2019; Kundur et al., 1994):

$\Delta \overline{P_{D}}=D \Delta \bar{\omega} \rightarrow D=\frac{\Delta \overline{P_{D}}}{\Delta \bar{\omega}}$

The damping constant (D) is the percentage change that occurs in the frequency or angular velocity for the given percentage load change. Its typical value is around 1-2\%. For example, if there is a frequency change of $1 \%$ in a load change of $1 \%, \mathrm{D}=1 / 1=1$. Accordingly, if Equations (6), (7), and (8) are combined, the linearized and simplified model of a generator of which output is angular velocity or frequency, is obtained (Tabakh, 2020; Tiryaki and Gün, 2019; Kundur et al., 1994):

$\Delta \overline{P_{m}}-\Delta \overline{P_{L}}=(M s+D) \Delta \bar{\omega}$

In this study, it was assumed that there is no load change or the load is constant $\left(\Delta \overline{P_{L}}=0\right)$ since the application was performed in a hydroelectric power plant operating as a single area (Tabakh, 2020; Tiryaki and Gün, 2019).

\section{Controller design}

The parameters of the hydroelectric power plant consisting of the simplified and linearized turbine and generator blocks are given in Table 1.

Table 1: Calculated values of the parameters of the simplified generator model.

\begin{tabular}{|c|c|c|c|}
\hline Symbol & Name & Value & Unit \\
\hline $\boldsymbol{T}_{\boldsymbol{w}}$ & $\begin{array}{c}\text { Turbine inlet water } \\
\text { time delay }\end{array}$ & 2 & sec \\
\hline $\boldsymbol{M}$ & $\begin{array}{c}\text { Angular Momentum } \\
\text { of the Generator }\end{array}$ & 8 & $\begin{array}{c}\text { (MW- } \\
\text { sec/MVAr) }\end{array}$ \\
\hline $\boldsymbol{D}$ & Damping Constant & 1 & $\%$ \\
\hline
\end{tabular}

The values given in Table 1 are used as simplified and linearized hydroelectric power plant parameters in many studies in the literature (Tabakh, 2020; Tiryaki and Gün, 2019; Naghizadeh et al., 2012).

The block diagram used to control the system was developed in MATLAB R2020a (MATLAB, R2020a) and is presented in Figure 1. 


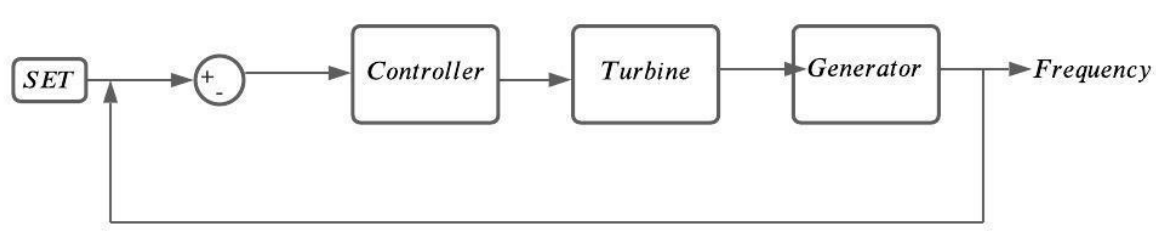

Figure 1: Control block diagram of the hydroelectric power plant.

Five controllers that are PI, PID, FGPI, ANFIS PI, and ANFIS PID have been used to control the power plant.

The PI and PID controllers' parameters that were calculated and optimized according to the system response curve method are presented in Table 2 (Tabakh, 2020; Yüksel, 2009).

Table 2: The parameters of the conventional PI and PID controllers.

\begin{tabular}{|c|c|c|c|}
\hline Controller & $\mathbf{K}_{\mathbf{P}}$ & $\mathbf{K}_{\mathbf{I}}$ & $\mathbf{K}_{\mathbf{D}}$ \\
\hline PI & 1.2000 & 0.2000 & $*$ \\
\hline PID & 1.6000 & 0.440 & 1.4400 \\
\hline
\end{tabular}

The FGPI controller is designed based on providing parameter changes of a PI controller with a fuzzy logic controller. The fuzzy logic controller works based on fuzzy rules which are given by the controller designer. Generally, the design has a knowledge working of the plant system to be controlled.

The fuzzy logic control system comprises of two inputs. The first input is an error obtained by contrasting the reference input signal and output signal, while the second input is the change in the error with respect to time. The fuzzy logic controller comprises of three parts fuzzification, inference mechanism, and defuzzification. Here, the PI controller's parameters are applied to the system by adapting to the changing system dynamics.

\subsection{Proposed ANFIS-based controllers}

The adaptive network-based fuzzy inference system technique was first introduced by Jang in 1993 (Jang, 1993). ANFIS is a simple data learning technique that uses fuzzy logic to convert inputs given via highly interconnected neural network processing elements and information links into the desired output (Jang, 1993).

Basically, the ANFIS system applies the technique of artificial neural network learning rules to determine and set the structure and parameters of fuzzy inference systems. The system has the ability to learn the data given to it through fuzzy rules (Lutfy et al., 2009; Lutfy et al., 2011). Jang developed a type of hybrid neuro-fuzzy inference expert system that works in the Takagi-Sugeno type fuzzy inference system (Jang, 1993).

The architecture of ANFIS consists of five layers. Among these layers, both the first and fourth layers consist of adaptive neurons. However, the second, third, and fifth layers consist of fixed neurons. Adaptive neurons are associated with their own parameters and are updated appropriately with each of them in the next iteration, and the fixed nodes lack any parameters (Abraham, 2005; Alhanafy et al., 2010; Nazmy et al. 2010; Milosavljevic et al., 2008 ). 
Considering two fuzzy rules based on the first-order Sugeno model:

- Rule 1: (if $\left.\mathrm{x}=\mathrm{A}_{1}\right)$ and (if $\left.\mathrm{y}=\mathrm{B}_{1}\right)$, then $\quad\left(\mathrm{f}_{1}=\mathrm{p}_{1} \mathrm{x}+\mathrm{q}_{1} \mathrm{y}+\mathrm{r}_{1}\right)$

- Rule 2: (if $\left.\mathrm{x}=\mathrm{A}_{2}\right)$ and (if $\left.\mathrm{y}=\mathrm{B}_{2}\right)$, then $\quad\left(\mathrm{f}_{2}=\mathrm{p}_{2} \mathrm{x}+\mathrm{q}_{2} \mathrm{y}+\mathrm{r}_{2}\right)$

where, $x$ and $y$ are inputs, $A_{i}$ and $B_{i}$ are fuzzy sets. $f_{i}$ is the outputs within the fuzzy region, $p_{i}$, $\mathrm{q}_{i}$ and $\mathrm{r}_{\mathrm{i}}$ are design parameters determined in the training process. To implement these two rules, the ANFIS architecture was demonstrated in Figure 2.

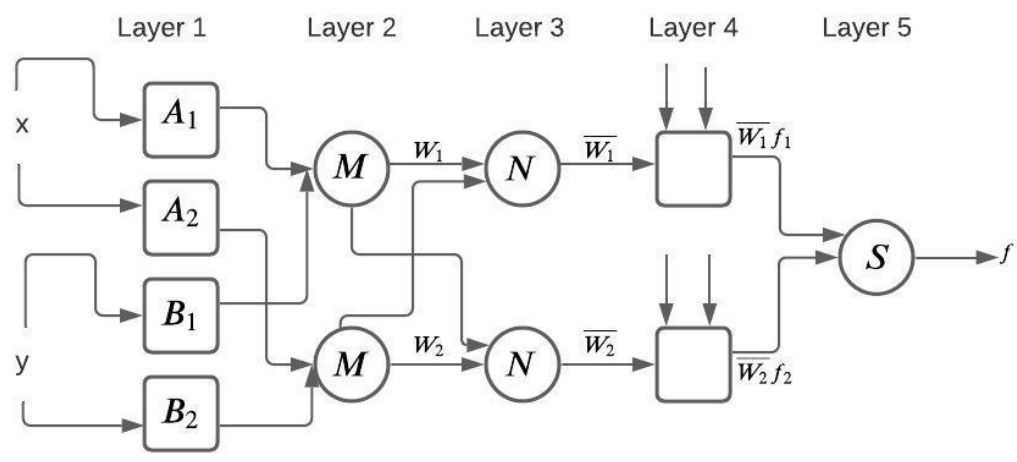

Figure 2: ANFIS architecture.

Layer 1 is the fuzzification layer. The outputs of layer 1 are the fuzzy membership degree of the inputs and are given as follows:

$O_{i}^{1}=\mu_{A_{i}}\left(x_{1}\right) ; i=1,2$

$O_{i}^{1}=\mu_{B_{i-2}}\left(x_{2}\right) ; i=3,4$

where, $\mathrm{x}$ and $\mathrm{y}$ are the inputs of the layers, $\mathrm{A}$ and $\mathrm{B}$ are a linguistic labels, and $\mu_{A_{i}}(x)$ and $\mu_{B-2}(y)$ functions can be selected as any fuzzy membership function.

The output of layer 2 is a fixed node labeled M, which is the product of all incoming signals. The outputs of this layer can be represented as follows:

$O_{i}^{2}=w_{i}=\mu_{A_{i}}(x) \times \mu_{B_{i}}(x) ; i=1,2$

Layer 3 is the normalization layer and is a fixed node labeled $\mathrm{N}$.

$O_{i}^{3}=\overline{w_{1}}=\frac{w_{i}}{w_{1}+w_{2}} ; i=1,2$

where $\overline{w_{1}}$ represents the normalized output of layer 3 .

Layer 4 is the defuzzification layer. The output of each node in this layer is the product of normalized strength and a first-order polynomial.

$O_{i}^{4}=\bar{w}_{l} f_{i}=\bar{w}_{l} .\left(p_{i} x_{1}+q_{i} x_{2}+r_{i}\right) ; i=1,2$ 
where $\left(p_{i}, q_{i}, r_{i}\right)$ rule is the set out output parameters for $i$, and $f_{i}$ is the $i$ order polynomial.

Layer 5 is the summation neuron and is a fixed node that calculates the output as the sum of all incoming signals.

$O_{i}^{5}=y=\sum_{i=1} \overline{w_{l}} . f_{i}=\frac{\sum_{i=1} w_{i} f_{i}}{w_{i}} ; i=1,2$

The flow chart of ANFIS is given in Figure 3.

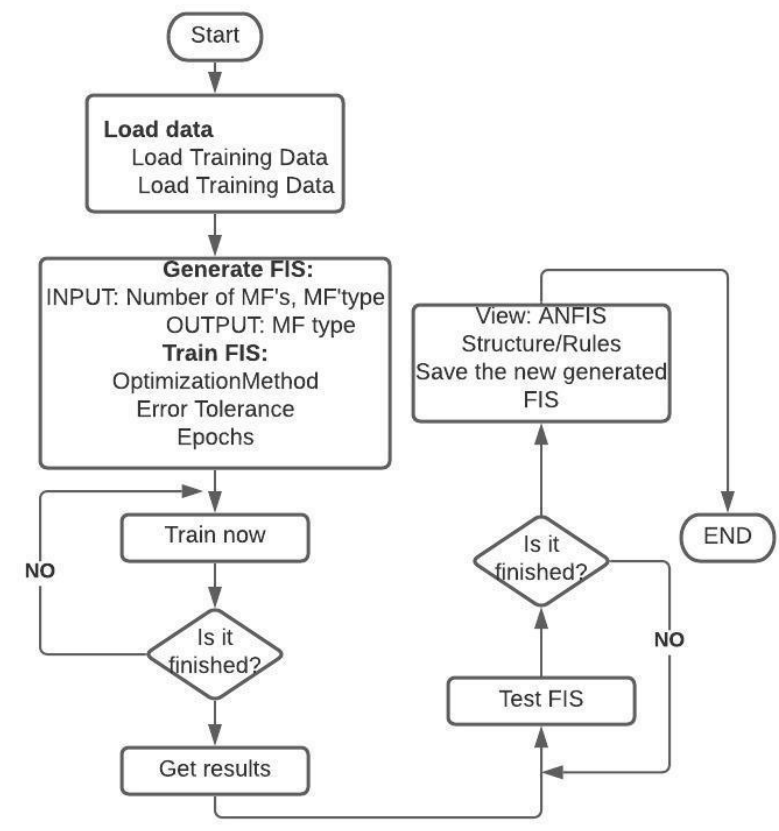

Figure 3:Flow chart of the ANFIS structure.

The block diagram for the ANFIS-PID is given in Figure 4, the same diagram can be used for the ANFIS-PI controller by just setting the derivative coefficient $\left(\mathrm{K}_{\mathrm{d}}\right)$ to zero.

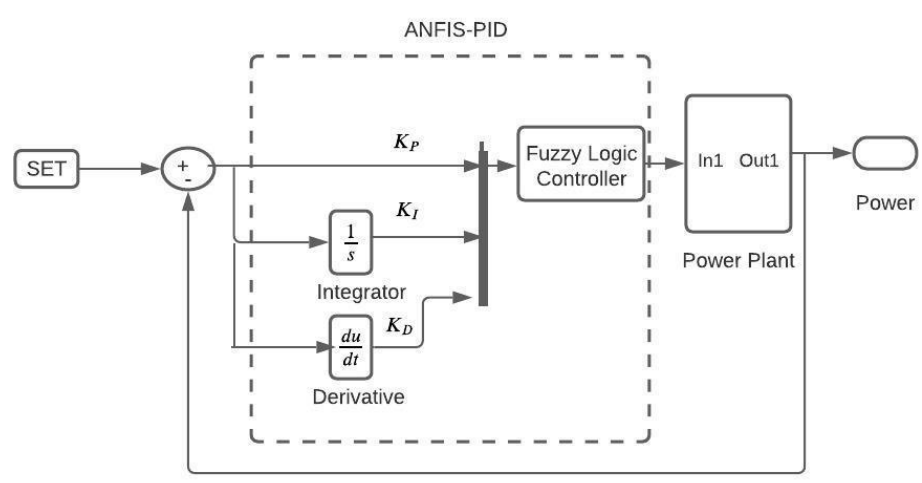

Figure 4:Block diagram of the ANFIS controller.

In Figure 4, the hydroelectric power plant is dynamic and conventional PI/PID controller alone cannot track dynamic changes of the plant. Therefore, ANFIS PI/PID controller can be 
able to track the changes in the output of the plant and provide appropriate control signals (Tabakh, 2020).

\subsection{Data collection}

In order to collect the data of the ANFIS-PI controller used in this study, the time-varying $K_{P}$ and $\mathrm{K}_{\mathrm{I}}$ parameters of the conventional PI controller were taken as the system input. The timevarying total output of the same controller was taken as the system output.

1 second was chosen as the sampling time to receive the data. A total of 65 data were used. About $75 \%$ of the data was used for the training of the created Sugeno-based ANFIS model, and the rest was used for testing the accuracy of the system (Tabakh, 2020).

Likewise, similar method was used to collect the data of the ANFIS-PID controller. 72 data were used, and. $75 \%$ of the data was used for the training of the ANFIS model, and the rest was used for validating (Tabakh, 2020).

\subsection{Training}

Training is a learning process of the developed model. The model is trained until the results are achieved with minimum errors. Choosing the appropriate dataset is very important for proper training and verification.

The number of epochs selected for the training of ANFIS-PI and ANFIS-PID controllers was determined as optimal 200. The minimum test error can be obtained in the first test. For the correct dataset, the test error decreases as training proceeds to a jump point. Excessive adaptation occurs when training exceeds this point. Optimization methods are used to learn about training data. During the learning process, the parameters of memberships are updated. There are two methods in MATLAB for ANFIS parameter optimization: The hybrid optimization method, a combination of least-squares and backpropagation gradient descent methods, and the backpropagation optimization method. As a result of the trials done for this study, the hybrid method was chosen as the most suitable method for the model. Error tolerance is used as the training stop criterion related to error size. Training will cease after the training data error remains within this tolerance. The conditions of ANFIS-PI and ANFISPID controllers' training errors according to the number of iterations are presented in Figure 5.

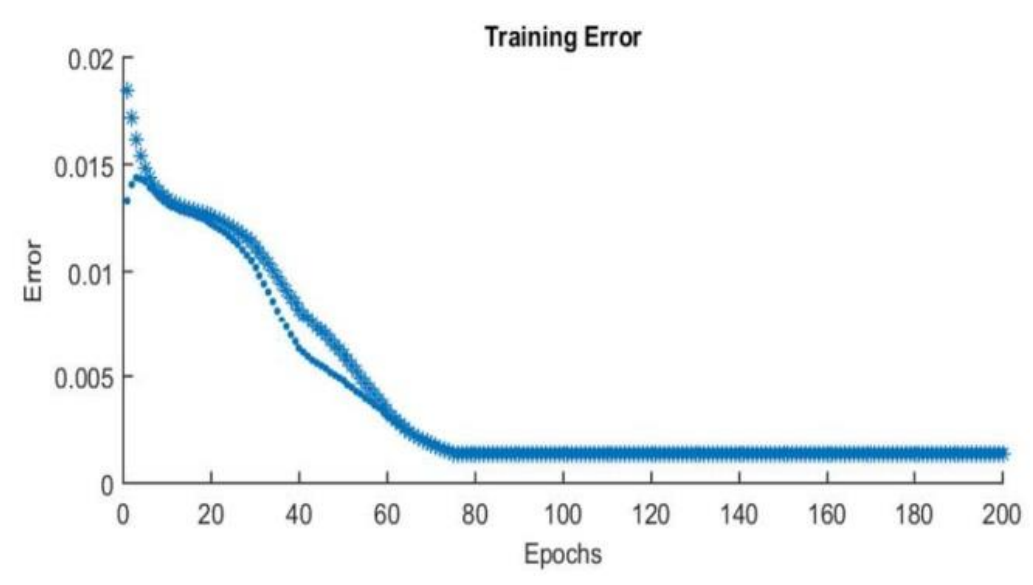

(a) ANFIS-PI 


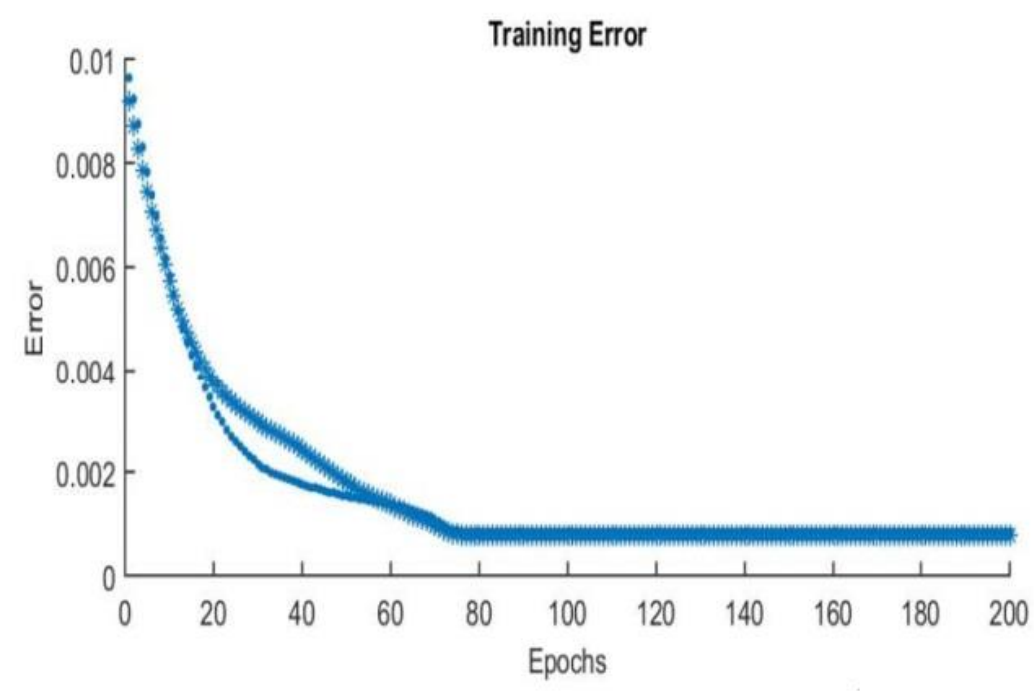

(b) ANFIS-PID

Figure 5: Training errors.

In Figure 5 (a) and (b), three membership functions were used for each input of the ANFISPI controller, and the average test error (Mean Squared Error-MSE) for the ANFIS PI and ANFIS PID were found to be 0.0013753 , and 0.00076873, respectively (Tabakh, 2020).

\subsection{Validation}

The validation dataset is used to test the generalization capacity of the fuzzy inference model produced by ANFIS and to validate the model. This validation is performed by applying the inspection data to the model and then observing how well the model responds to these data. Figure 6 demonstrated the error graphs of the validation data used for the ANFIS-PI and ANFIS-PID controllers.

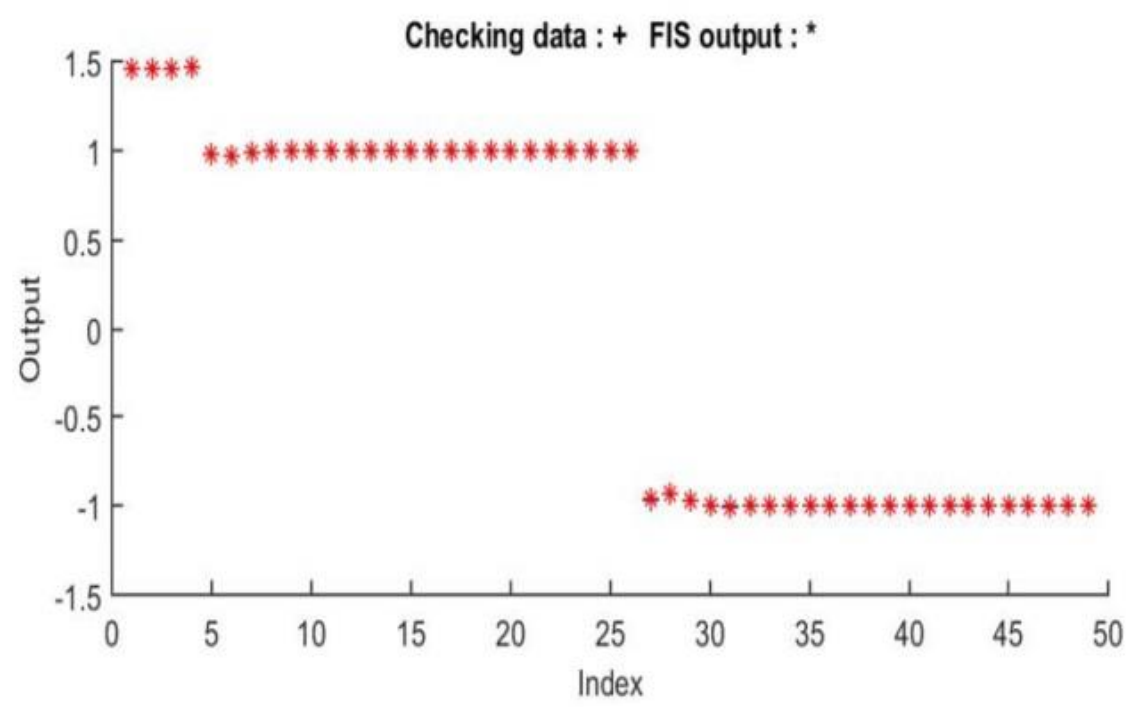

(a) ANFIS-PI 


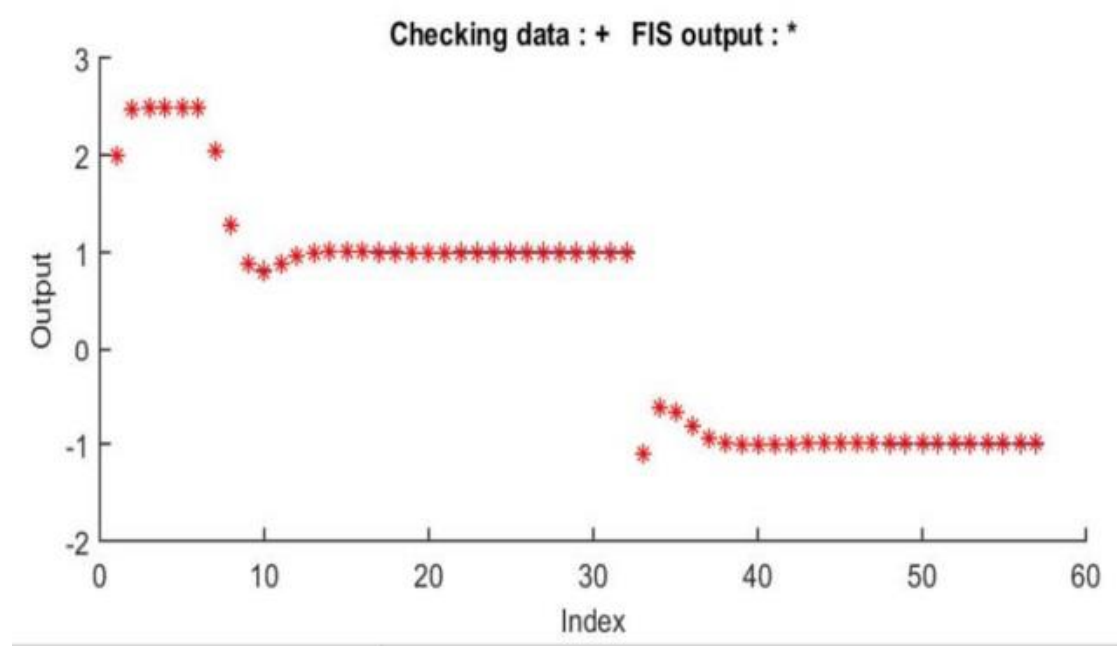

(b) ANFIS-PID

Figure 6: Validation errors.

In Figure 6 (a) and (b), the average test error (Mean Squared Error-MSE) for the validation dataset of the ANFIS PI and ANFIS PID were found to be 0.0015078 and 0.0008374 respectively (Tabakh, 2020).

\section{Results and discussion}

The production of electricity by hydroelectric power plants depends on precipitation conditions, its total energy contribution changes every year, but approximately $16 \%$ of electrical energy (Zayoud, 2016) is produced from water worldwide. The size of the energy produced increases the importance of controlling these power plants. The simulation results for the control of the power plants using conventional controllers, FGPI, ANFIS PI and ANFIS PID controllers are shown in Figure 7 and Table 3. A 5\% band was used to make a comparison.

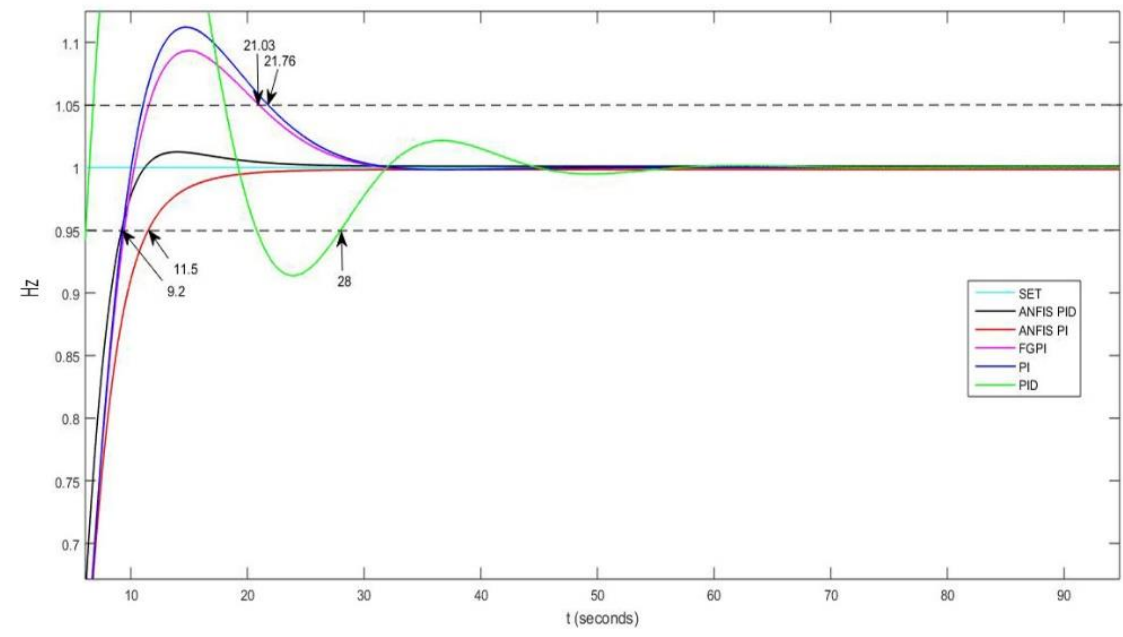

Figure 7: Simulation results. 
Table 3: Simulation results.

\begin{tabular}{|c|c|c|c|c|c|}
\hline & ANFIS-PID & ANFIS-PI & FGPI & PI & PID \\
\hline $\begin{array}{c}\text { Settling } \\
\text { Time } \\
\text { (seconds }\end{array}$ & 9.2 & 11.5 & 21.03 & 21.76 & 28 \\
\hline $\begin{array}{c}\text { Overshoot } \\
(\%)\end{array}$ & 1.2 & 0 & 9.4 & 11.2 & 35.04 \\
\hline
\end{tabular}

One can see that in Figure 7 and Table 3, ANFIS-based controllers yield much better results than other controllers. At this point, the fact that the PI controller gave results much better than the PID controller and close to the FGPI controller proved the accuracy of its being generally preferred in hydroelectric power plants. It should be noted that while all the three controllers have settling time longer than 20 seconds, the PID controller has the longest settling time.

Among ANFIS-based controllers that give the fastest results, the ANFIS-PID controller is observed to be 2.3 seconds ahead of the ANFIS-PI controller in terms of settling time. However, the overshoot value of the ANFIS-PI controller is 0, while the ANFIS-PID controller has an overshoot value of $1.2 \%$. In frequency control applications, systems with quick response are more preferred.

\section{Conclusion}

As can be understood from the simulation results, when ANFIS-based controllers are used, the system gives more good results than other controllers in terms of both settling time and overshoot value. Accordingly, the use of modern control techniques such as ANFIS-based controllers instead of conventional controllers in the frequency control of such hydroelectric power plants seems to be appropriate.

The parameters of conventional controllers, which are generally preferred in the installation phase of existing hydroelectric power plants, are determined according to the features of the power plant's initial establishment conditions. However, as the power plant lifespan increases, these parameters cannot adapt to changing system dynamics. Since this situation causes loss of efficiency in power plants, energy losses is unacceptable, it is necessary to design controllers for hydroelectric power plants with modern controllers in order to provide their self-adaptation to the continuously changing system dynamics.

Modern control methods such as Adaptive Neuro-Fuzzy Inference System based ANFIS-PI and ANFIS-PID controllers, have been applied in a hydroelectric power plant control, the effectiveness of the control system increases the efficiency of the power plant, and its depreciation decreases. Considering that these improvements were made for a single hydroelectric power plant and that $16 \%$ of the energy needs worldwide is met with this type of power plants. Furthermore, an advantage will be provided to the consumer with a decrease in electricity production costs. Most importantly, the production of energy from fossil fuels, 
which are increasingly depleted and which pollute the environment and create danger, will be reduced in this way.

\section{References}

Abraham A. Adaptation of fuzzy inference system using neural learning. In: Fuzzy systems engineering. Berlin: Springer, 2005, pp. 53-83.

Alhanafy TE, Zaghlool $\mathrm{F}$ and Moustafa ASED. Neuro fuzzy modeling scheme for the prediction of air pollution. Journal of American Science 2010; 6.12: 605-616.

Aurelien YT, Hervé SA and Martial NG. Synthesis of a digital corrector for frequency control in hydroelectric power plants. Control Science and Engineering 2019; 2.1: 36-49.

De Jaeger E, Janssens N, Malfliet B, et al. Hydro turbine model for system dynamic studies. IEEE Transactions on Power Systems 1994; 9.4: 1709-1715.

Eke İ. Modeling and simulation of hydroelectric power plants. Msc Thesis, Kirıkkale University, Turkey, 2004. (In Turkish)

Electricity Generation Company. (2019) Annual Report. Report for the Department of Press and Public Relations. Report no. 2019, 31 December. Ankara

Gheisarnejad M and Khooban MH. Design an optimal fuzzy fractional proportional integral derivative controller with derivative filter for load frequency control in power systems. Transactions of the Institute of Measurement and Control 2019; 41.9: 2563-2581.

Jang JS. ANFIS: adaptive-network-based fuzzy inference system. IEEE Transactions on Systems, Man and Cybernetics 1993; 23.3: 665-685.

Kocaarslan İ and Çam E. Load-frequency control of two area interconnected power plants. In: Automatic Control National Meeting (TOK), Ankara, Turkey, 9-11 September 2002, pp. 631637, Ankara: TOK. (In Turkish)

Kundur P, Balu NJ and Lauby MG. Power system stability and control. New York: McGrawhill, 1994.

Lutfy OF, Noor MS, Marhaban MH, et al. A genetically trained adaptive neuro-fuzzy inference system network utilized as a proportional-integral-derivative-like feedback controller for non-linear systems. Proceedings of the Institution of Mechanical Engineers, Part I: Journal of Systems and Control Engineering 2009; 223.3: 309-321.

Lutfy OF, Noor MS, Marhaban MH, et al. Non-linear modelling and control of a conveyorbelt grain dryer utilizing neuro-fuzzy systems. Proceedings of the Institution of Mechanical Engineers, Part I: Journal of Systems and Control Engineering 2011; 225.5: 611-622.

MATLAB R2020a, Reference Manual, Licence Number: 40827100, 2020.

Milosavljevic A, Stoimenov L and Rancic D. An algorithm for automatic generation of fuzzy neural network based on perception frames. In: 9th WSEAS International Conference on Neural Networks, Sofia, Bulgaria, 2-4 May 2008, pp. 215-220. Sofia: WSEAS. 
Naghizadeh RA, Jazebi S and Vahidi B. Modeling hydro power plants and tuning hydro governors as an educational guideline. International Review on Modelling and Simulations 2012; 5.4: 1780-1790.

Nazmy T, El-Messiry H, Al-Bokhity B, et al. Adaptive neuro-fuzzy inference system for classification of ECG signals. Journal of Theoretical and Applied Information Technology 2010; 12.2: 71-76.

Qian D and Jianqiang Y. A new control system design for a small hydro-power plant based on particle swarm optimization-fuzzy sliding mode controller with Kalman estimator: a comment. Transactions of the Institute of Measurement and Control 2013; 35.8: 1152.

Rinaldi G, Cucuzzella M and Ferrara A. Sliding mode observers for a network of thermal and hydroelectric power plants. Automatica 2018; 98: 51-57.

Sevilgen SH and Erdem HH. Generation planning methodology based on load factor for hydroelectric power plants. Advances in Mechanical Engineering 2014; 6: 282513.

Shahgholian G. Power system stabilizer application for load frequency control in hydroelectric power plant. International Journal of theoretical and Applied Mathematics 2017; 3.4: 148 .

Simani S, Alvisi S and Venturini M. Fuzzy control techniques applied to wind turbine systems and hydroelectric plants. In: 2019 IEEE International Conference on Fuzzy Systems (FUZZ-IEEE), New Orleans, Louisiana, USA, 23-26 June 2019, pp. 1-6. New Orleans: IEEE.

Ahmadi, Sajjad, et al. "FUZZY aided PID controller is optimized by GA algorithm for Load Frequency Control of Multi-Source Power Systems." 2020 IEEE 18th World Symposium on Applied Machine Intelligence and Informatics (SAMI). IEEE, 2020.

Yuniahastuti, Irna Tri, Izza Anshori, and Imam Robandi. "Load frequency control (LFC) of micro-hydro power plant with Capacitive Energy Storage (CES) using Bat Algorithm (BA)." 2016 International Seminar on Application for Technology of Information and Communication (ISemantic). IEEE, 2016.

Khatri, Megha, and Atul Kumar. "Stability Inspection of Isolated Hydro Power Plant with Cuttlefish Algorithm." 2020 International Conference on Decision Aid Sciences and Application (DASA). IEEE, 2020.

Tabakh R. Application of modern control methods in power plants. Msc Thesis, Istanbul University - Cerrahpaşa, Turkey, 2020. (In Turkish).

Tiryaki $\mathrm{H}$ and Gün A. Frequency control in a hydroelectric power plant with modern optimization methods. International Journal of Engineering Research and Development 2019; 11.1: 266-274.

Vournas CD and Zaharakis A. Hydro turbine transfer functions with hydraulic coupling. IEEE Transactions on Energy Conversation 1993; 8.3: 527-532 (1993). 
Frequency Control in a Hydroelectric Power Plant with Adaptive Neuro-Fuzzy Inference System-Based Modern Controllers

Yüksel İ. Automatic control system dynamics and control systems, Ankara: Nobel Press, 2009. (In Turkish)

Zayoud A. Circulating fluidized bed combustor towards third generation of oxy-fuel combustion, PhD Thesis, Indian Institute of Technology Guwahati, India, 2016. 